\title{
COVID-19 Lock-Down Affecting Mental Health in Thailand; Review and Situation
}

\author{
Pholputta, L., ${ }^{1,5}$ Glubvong, M., ${ }^{2}$ Amornmahaphun, S., ${ }^{3}$ Jiranukul, J., ${ }^{4}$ Thongkrajai, P. ${ }^{5}$ and \\ Nithikathkul, C. ${ }^{1,5^{*}}$ \\ ${ }^{1}$ Program in Health Science, Faculty of Medicine, Mahasarakham University, Thailand \\ E-mail: lovelyaoy.ladda@gmail.com \\ ${ }^{2}$ Faculty of Nurse, Western University, Thailand \\ ${ }^{3}$ Mental Health Department, Roi-et Hospital, Roi-et, Thailand \\ ${ }^{4}$ Department of Medicine, Faculty of Medicine, Mahasarakham University, Thailand \\ ${ }^{5}$ Tropical and Parasitic Diseases Research Unit, Faculty of Medicine, Mahasarakham University, Thailand \\ E-mail: nithikethkul2016@gmail.com*
}

*Corresponding Author

DOI: https://doi.org/10.52939/ijg.v17i5.2023

\begin{abstract}
Major depressive disorder and generalized anxiety disorder are among the most commonly diagnosed mental illnesses in Thailand; both are associated with a high societal and economic burden. Treatment for major depressive disorder and generalized anxiety disorder consists of pharmacological and psychological interventions. Three commonly used psychological interventions are cognitive behavioral therapy, interpersonal therapy, and supportive therapy. The Unprecedented crisis produced by the COVID-19 pandemic produced a mental health situation with a severe impact on both seniors and adolescents. An analysis of the impact on COVID-19 on mental health in Thailand was conducted by an investigation of data from the Roi-et public health office in Roi Et province. The data showed that in the years 2016, 2017, 2018, 2019 and 2020 there were respectively 1.18, 1.36, 1.51,1.96 and 1.93 of residents with depression. Among senior citizens in the province depression was more frequent with 2.99, 3.41, 3.60, 3.99 and 5.25 of seniors diagnosed as depressed in the years 2014, 2015, 2016, 2017 and 2018. In the era of the COVID-19 outbreak there was a higher prevalence of psychological health problems among seniors and adolescents. The crucial outcome from spatial analysis using GIS showed the highest number of mental health problems in Kaset Wisai district and the lowest prevalence in Thung Kao Lunang district. These findings suggest that the government needs to pay more attention to psychological health among elderly people while combating COVID-19.
\end{abstract}

\section{Introduction}

Depression is a common illness worldwide, with an estimated $3.8 \%$ of the population affected, including $5.0 \%$ among adults and $5.7 \%$ among adults older than 60 years (WHO, 2021). Depression is a leading cause of disability and suicide is a major contributor to the overall global burden of disease (WHO, 2020). Unrecognized and untreated depression leads to serious consequences, including functional decline, poor quality of life, increased morbidity and mortality (Miller, 2019), and can lead to suicide (close to 800,000 people die due to suicide every year (WHO, 2020). Depression commonly occurs in older adults with chronic conditions or functional impairments. The prevalence of geriatric depressive disorders in Asian countries ranges from $12 \%$ to 34 \%. In Sri Lanka, Indonesia, Vietnam, Japan, Indian, Malaysia, and Thailand the prevalence of depression is respectively: $27.8 \%, 12.7 \%, 33.8 \%, 17.2 \%$,
34.4\%, 16.5\% and 12\% (Malhotra et al., 2010, Pilania et al., 2019, Vanoh et al., 2016 and Anantapong et al., 2017).

COVID-19 is a new strain of coronavirus that emerged in 2019. On 11 March 2020, COVID-19 was characterized by the World Health Organization as a pandemic. China reported the first cases of what is now referred to as COVID-19 on December 31, 2019. WHO is working closely with the National Health Commission in Thailand responding to the COVID-19 outbreak (WHO, 2020). Globally, there have been 55,326,907 confirmed cases of COVID19 , including $1,333,742$ deaths by June of 2020 and 223 million cases and between 4.5 million and 15 million deaths by September 2021 (WHO, 2020, 2021). The COVID-19 pandemic has had an unprecedented effect on the lives of people, irrespective of social demographics. However, there 
is currently very little known about the broader impact of COVID-19 on global mental health, in general, and geriatric mental health, in particular (Letter to the Editor, 2020). Social distancing, though a major strategy to fight COVID-19, is also a major cause of loneliness, particularly in facilities like nursing-care or old-age homes. Social distancing is an independent risk factor for depression, anxiety disorders, and suicide (Centers for Disease Control and Prevention, 2020). The prevalence of depressive symptoms in the USA was more than three-fold higher during COVID-19 compared with before the COVID-19 pandemic (Centers for Disease Control and Prevention, 2020). The COVID-19 pandemic also negatively affected older adults' mental health (Krendl and Perry, 2020).

Major depressive disorder and generalized anxiety disorder are among the most commonly diagnosed mental illnesses in Thailand; both are associated with a high societal and economic burden. Treatment for major depressive disorder and generalized anxiety disorder consists of pharmacological and psychological interventions. Three commonly used psychological interventions are cognitive behavioral therapy, interpersonal therapy, and supportive therapy. The phenomenal nature of the mental health situation and trend of illness in seniors and adolescents was used to assess the effectiveness of the response. The data used in the analysis was from the Roi Et Province Public Health Office in Thailand. This retrospective study aimed to study the prevalence of depressive disorder in Thailand.

\section{Methods}

\subsection{Study Design}

This retrospective study is about the prevalence of depressive disorder in adults of Thailand (aged 18 years and over) for study period of 5 years from 2016 - 2020 and the prevalence of the depressive disorder in elderly people during the study period of 5 years from 2014 - 2018 in the Roi Et Province, Thailand (Flow chart 1). The data were retrieved from the depressive disorder investigation form, Health Data Center (HDC) reports made to the Roi Et Provincial Public Health Office, (Department of Mental Health, Ministry of Public Health, Thailand, 2020).

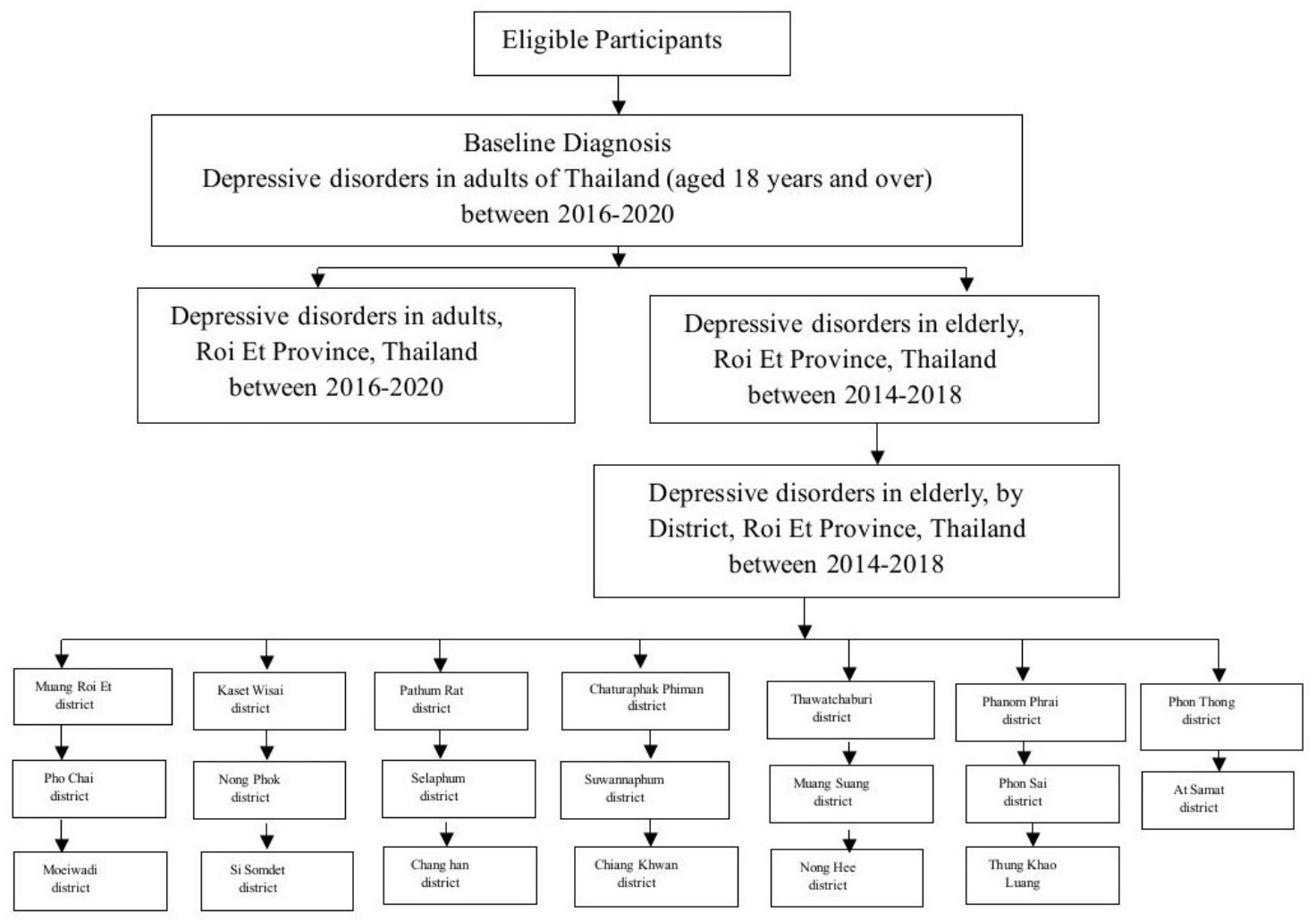

Flow chart 1: Retrospective study design and study flow chart 


\subsection{Statistical Analysis}

The data were processed and statistically analyzed by using Microsoft Excel and SPSS for Windows version 25.0. Data was checked and cleaned. Data was analyzed with addition of descriptive statistics including frequency and percentage of depressive disorder.

\subsection{Ethics Statement}

This study was reviewed and approved on April 22, 2020 by the Ethics Committee of Mahasarakham University, Thailand (registration number 112/2020).

\section{Results}

During the study period, depressive disorder for adults aged 18 years and over, was reported between January $1^{\text {st }}, 2016$ and December $31^{\text {st }}, 2020$ in Thailand. In the period of 2016-2020 the overall prevalence of depressive disorder was $1.34,1.45$, $1.65,1.81$ and 2.01 respectively. For the overall five years period (2016-2020) the average prevalence of depressive disorder was determined to be $1.65 \%$ and ranged between $1.34 \%$ and $2.01 \%$. The spatial prevalence of depressive disorder in Thailand was focused mostly in the Northeastern region, followed by the Central region, Northern region, Bangkok, Western region, South region and Eastern region. The percentage prevalence of depression in the general population was $1.82 \%$ in the Northeastern region, $1.80 \%$ in the Central region, $1.75 \%$ in the Northern region, $1.69 \%$ in the Bangkok region, $1.67 \%$ in the Western region, $1.66 \%$ in the Southern region, $1.30 \%$ in the Eastern region respectively (Table 1). The crucial outcome from spatial analysis using GIS showed the highest and lowest prevalence in Northeastern region and Eastern region (Figure 1).

Table 1: Prevalence of Depressive disorder for adults aged 18 years and over, in Thailand from 2016-2020

\begin{tabular}{|l|c|c|c|c|c|c|c|c|}
\hline \multirow{2}{*}{ Year } & \multicolumn{9}{|c|}{ Prevalence of depressive disorders (\%) } & \multirow{2}{*}{$\begin{array}{c}\text { Average } \\
(\%)\end{array}$} \\
\cline { 2 - 11 } & $\begin{array}{c}\text { Western } \\
\text { region }\end{array}$ & $\begin{array}{c}\text { Northern } \\
\text { region }\end{array}$ & $\begin{array}{c}\text { Central } \\
\text { region }\end{array}$ & $\begin{array}{c}\text { Eastern } \\
\text { region }\end{array}$ & $\begin{array}{c}\text { Northeastern } \\
\text { region }\end{array}$ & $\begin{array}{c}\text { Southern } \\
\text { region }\end{array}$ & \multicolumn{2}{c|}{ Bangkok } \\
\hline 2016 & 1.52 & 1.19 & 1.28 & 1.06 & 1.43 & 1.35 & 1.60 & 1.34 \\
\hline 2017 & 1.39 & 1.32 & 1.49 & 1.19 & 1.59 & 1.50 & 1.67 & 1.45 \\
\hline 2018 & 1.68 & 1.82 & 1.64 & 1.34 & 1.80 & 1.59 & 1.69 & 1.65 \\
\hline 2019 & 1.90 & 1.91 & 1.90 & 1.40 & 2.03 & 1.77 & 1.73 & 1.81 \\
\hline 2020 & 1.85 & 2.49 & 2.68 & 1.50 & 2.23 & 2.06 & 1.73 & 2.01 \\
\hline
\end{tabular}

Prevalence of depressive disorders, Thailand

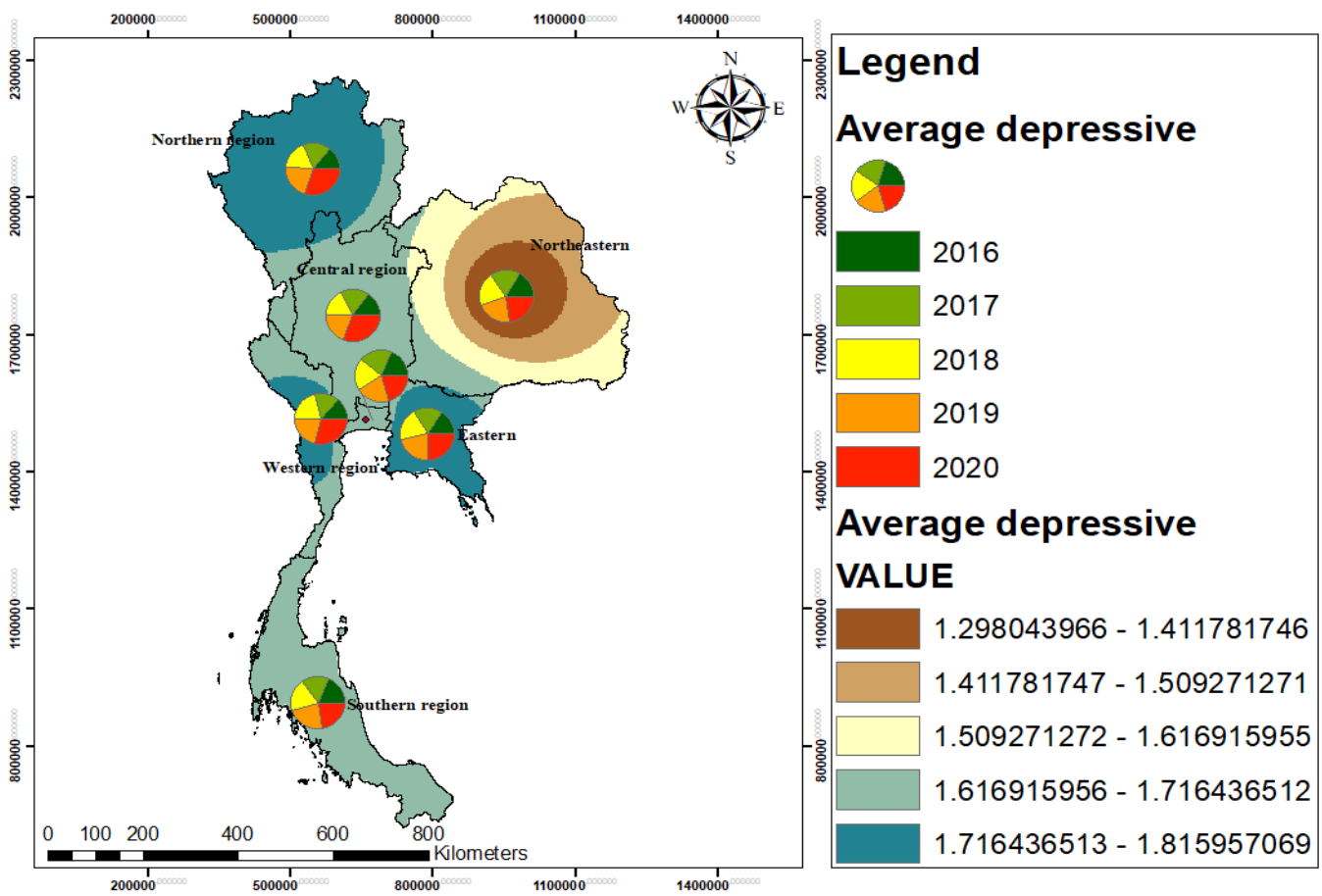

Figure 1: Prevalence of Depressive disorder for adults aged 18 years and over, in Thailand from 2016-2020 
Table 2: Prevalence of Depressive disorders for adults aged 18 years and over, Roi Et province, Thailand from 2016-2020

\begin{tabular}{|c|c|}
\hline Year & Prevalence of depressive disorders (\%) \\
\hline 2016 & 1.18 \\
\hline 2017 & 1.36 \\
\hline 2018 & 1.51 \\
\hline 2019 & 1.96 \\
\hline 2020 & 1.93 \\
\hline
\end{tabular}

Table 3: Prevalence of Depressive disorder for the Elderly population, Roi Et province, Thailand from 2014-2018

\begin{tabular}{|c|c|}
\hline Year & Prevalence of depressive disorders (\%) \\
\hline 2014 & 2.99 \\
\hline 2015 & 3.41 \\
\hline 2016 & 3.60 \\
\hline 2017 & 3.99 \\
\hline 2018 & 5.25 \\
\hline
\end{tabular}

Table 4: Prevalence of Depressive disorder for the Elderly people by District, in Roi Et province, Thailand from 2014-2018

\begin{tabular}{|l|c|c|c|c|c|}
\hline \multirow{2}{*}{ District } & \multicolumn{5}{|c|}{ Prevalence of depressive disorders (\%) } \\
\cline { 2 - 6 } & 2014 & 2015 & 2016 & 2017 & 2018 \\
\hline Muang Roi Et district & 1.78 & 2.34 & 2.35 & 2.59 & 3.98 \\
\hline Kaset Wisai district & 10.76 & 11.26 & 11.38 & 12.00 & 14.00 \\
\hline Pathum Rat district & 2.94 & 3.44 & 3.46 & 4.00 & 5.46 \\
\hline Chaturaphak Phiman district & 2.94 & 3.44 & 3.46 & 4.00 & 5.46 \\
\hline Thawatchaburi district & 7.00 & 7.44 & 7.46 & 4.89 & 6.23 \\
\hline Phanom Phrai district & 3.02 & 3.42 & 3.52 & 3.86 & 5.79 \\
\hline Phon Thong district & 5.79 & 6.32 & 6.60 & 7.05 & 8.73 \\
\hline Pho Chai district & 0.60 & 1.20 & 1.58 & 2.07 & 3.68 \\
\hline Nong Phok district & 3.67 & 4.27 & 4.57 & 5.29 & 6.88 \\
\hline Selaphum district & 8.48 & 9.08 & 9.28 & 9.89 & 11.00 \\
\hline Suwannaphum district & 4.50 & 5.00 & 5.07 & 5.59 & 6.80 \\
\hline Muang Suang district & 1.20 & 1.60 & 2.00 & 2.49 & 3.65 \\
\hline Phon Sai district & 0.60 & 1.00 & 1.30 & 1.82 & 2.83 \\
\hline At Samat district & 0.80 & 1.20 & 1.60 & 3.19 & 4.33 \\
\hline Moeiwadi district & 0.68 & 1.08 & 1.48 & 1.88 & 2.72 \\
\hline Si Somdet district & 0.10 & 0.10 & 0.20 & 0.41 & 0.89 \\
\hline Chang han district & 2.24 & 2.54 & 3.04 & 3.44 & 4.30 \\
\hline Chiang Khwan district & 2.24 & 2.52 & 2.92 & 2.94 & 3.92 \\
\hline Nong Hee district & 0.40 & 0.90 & 1.07 & 1.49 & 3.77 \\
\hline Thung Khao Luang district & 0.05 & 0.10 & 0.10 & 0.14 & 0.70 \\
\hline
\end{tabular}

In the 2016 - 2020 period, the prevalence of depressive disorder for adults aged 18 years and over in Roi Et province, Thailand were respectively $1.18,1.36,1.51,1.96$ and 1.93. For the overall five years period (2016-2020) the average prevalence of depressive disorder was determined to be $1.59 \%$, and ranged from $1.18 \%$ to $1.95 \%$. (Table 2). During the study period depressive disorder for the elderly people was reported between January $1^{\text {st }}, 2014$ and December $31^{\text {st }}, 2018$ across all 20 districts in Roi Et Province, Thailand. 


\section{Depressive disorder in Elderly}

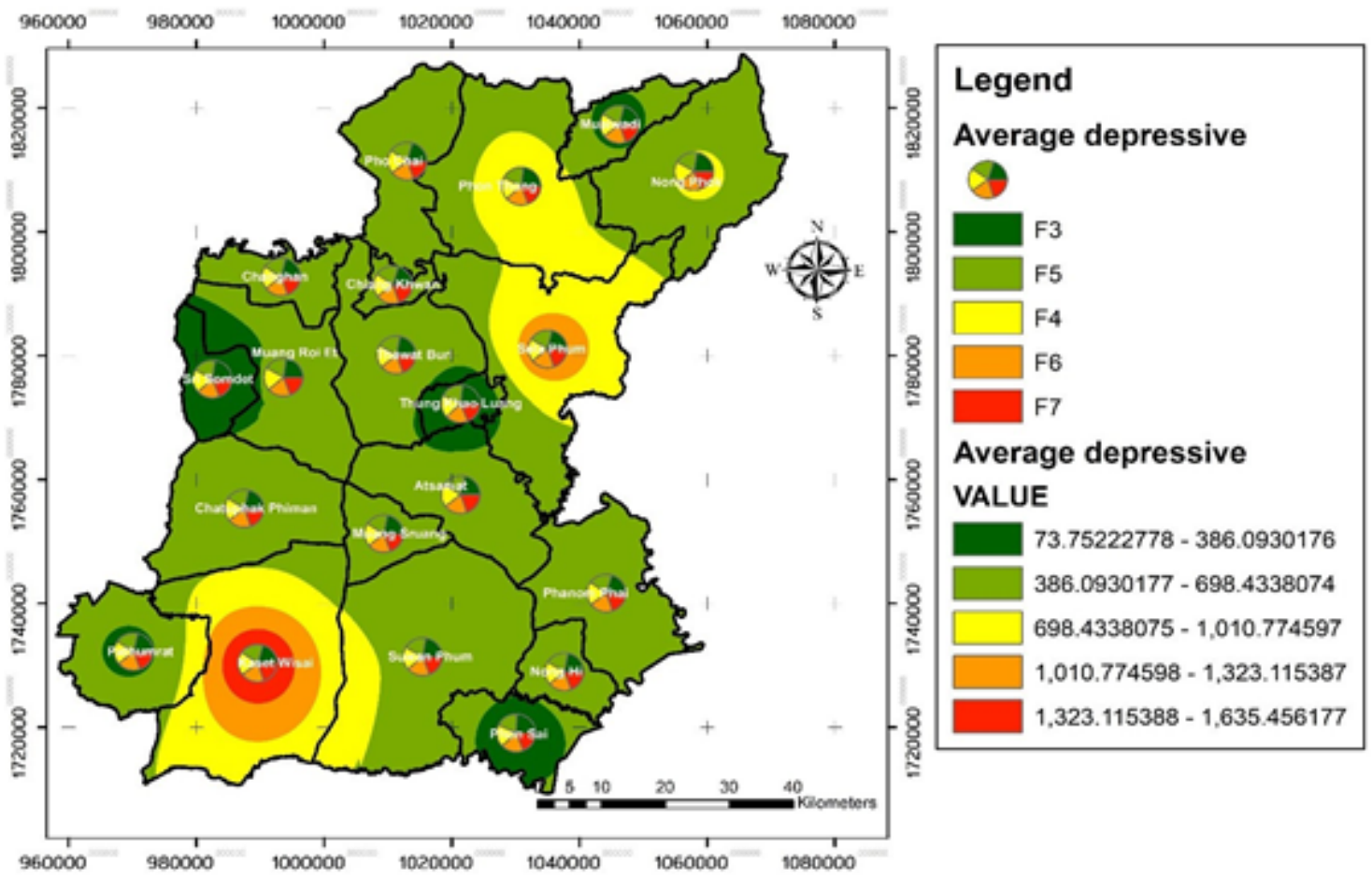

Figure 2: Prevalence of depressive disorder for the elderly people by District, Roi Et Province, Thailand from 2014-2018

In the 2014-2018 period, the prevalence of depressive disorders in the elderly were respectively, $2.99 \%, 3.41 \%, 3.60 \%, 3.99 \%$ and $5.25 \%$. For the overall five years period (2014-2018), the average prevalence of depressive disorder was determined to be $3.85 \%$ and it ranged between $2.99 \%$ and $5.25 \%$ (Table 3). Depressive disorder for the elderly population in Roi Et province is found at highest levels in the Kaset Wisai district and the lowest levels in Thung Khao Luang district (Table 4). The crucial outcome from spatial analysis using GIS showed the highest and lowest prevalence in Kaset Wisai district and Thung Kao Lunang district (Figure 2).

\section{Discussion and Conclusion}

For the overall five years period (2016-2020) the average prevalence of depressive disorder for adults aged 18 years and over was determined to be $1.65 \%$ and ranged between $1.34 \%$ and $2.01 \%$. Similar findings were reported by Clarke et al., (2019) (4.8\%). Studies conducted by WHO (2017), Gustavson et al., (2018), Qin et al., (2018) also reported the prevalence of depressive disorders to be $4.40 \%, 4.4 \%$ and $4.1 \%$ respectively. The findings reported by Zhou et al., (2014) found the prevalence of depressive symptoms among the rural population is higher than some southern cities in China.
Similar to Srinivasan et al., (2020) found about one in six adult women living in a rural area was depressed. Likely, Hu et al., (2019) found that the crude predicted probability of depression caseness was the highest in the rural group and similar to finding by Onuh et al., (2021) found the factors which significantly depressed respondents with incomes. The study found that in 2020, during the pandemic of COVID-19, it was found that prevalence of depressive disorders in Thailand and Roi Et province were $1.65 \%$ and $1.59 \%$ respectively, the prevalence depressive disorders in Roi Et province was $1.93 \%$, which is higher than in any previous year. The mental health consequences caused by the rapid and dramatic societal changes from the lockdown seem to include depression being on the increase. Similar findings were reported by Ettman et al., (2020) who found that the prevalence of depressive symptoms in the USA was more than3 fold higher during COVID-19 compared with before the COVID-19 pandemic. Studies conducted by Kim et al., (2020) also reported the perceived fear of COVID-19 in adults to be a risk factor for depression. Another study by Jia et al., (2020) recognized that the COVID-19 risk group was associated with increased stress, anxiety and depression, with the final multivariable models accounting for $7 \%-14 \%$ of variance in the rate of 
depression. The comparison of the prevalence rate of depression for adults aged 18 years and over in Thailand, and the rest of the world was also studied. It was found that the proportion of depressive disorder for adults aged 18 and over in Thailand (3.2\%) (Siriwanarangsun et al., 2004) was significantly lower than in the rest of the world (4.40\%) (WHO, 2017).

For the overall five years period (2014-2018) the average prevalence of depressive disorder for the elderly population in Roi Et province, Thailand was determined to be $3.85 \%$ which is higher than for Thailand as a whole. Similar findings were reported by Subramaniam et al., (2016) (3.7\%). Studies conducted by Liu et al., (2018), Anderson et al., (2013) and Denihan et al., (2000) also reported the prevalence of depression among the elderly to be $2.4-5.6 \%, 5.8 \%$, and $7.0 \%$ respectively.

Depressive disorder for the elderly people in Roi Et province is found at the highest levels in Kaset Wisai district and is lowest in Thung Kao Lunang district. Similar findings were reported by Li et al., (2016), WHO (2017) found that rural elders had more depressive symptoms than urban elders. However, both of these districts are rural, the unusual thing about Thung Kao Lunang district is the number of Swiss residents most of whom married local women and often actually live in Switzerland although some have relocated to Thailand. Studies conducted by $\mathrm{Hu}$ et al., (2019) found that the crude predicted probability of depression was the highest in the rural group, followed by the semi-urban group, and the lowest in the urban group and the increasing depression cases with the large rural disadvantage were substantially driven by socio-demographic characteristics and physical disability. A similar study was carried out by Sinha et al., (2013) and Nair et al., (2015) and found that depression is common in this rural population of older adults. The finding is quite similar to that reported by Kumari and Joseph (2020) which showed a significantly higher burden of depression in rural geriatric population as compared to a semi-urban setting.

In conclusion, this study in the 2016-2020 period, the prevalence of depressive disorders for adults aged 18 years and over, in Thailand were found to be respectively, $1.34 \%, 1.45 \%, 1.65 \%$, $1.81 \%$ and the study found that in 2020 , during the COVID-19 pandemic, it was $2.01 \%$ the highest level of that period. While in Roi Et province was $1.93 \%$ in 2019 and was higher every year than for Thailand as a whole. For the overall five years period (2014-2018) the average prevalence of depressive disorder for the elderly population in Roi Et province, Thailand was determined to be $3.85 \%$ and ranged between $2.99 \%$ and $5.25 \%$. The findings of the study can help program managers to implement a more comprehensive strategy in this community for intervention to promote mental health and prevent geriatric depression as this region has higher depression particularly in the elderly than the average for Thailand.

\section{Acknowledgements}

The authors would like to thanks partial grants support from Faculty of Medicine, Mahasarakham University and Tropical and Parasitic Diseases Research Unit, Faculty of Medicine. Special Thanks for Health Data Center (HDC) reports made to the Roi Et Provincial Public Health Office, (Department of Mental Health, Ministry of Public Health, Thailand for data of depressive disorders.

\section{References}

Anantapong, K., Pitanupong, J. and Werachattawan, N., 2017, Prevalence of Depression, and its Associated Factors among the Elderly in Songkhla Province, Thailand: Two-stage Cluster Sampling Study. Journal of Clinical Gerontology and Geriatrics, Vol. 8(2), 58-63.

Anderson, P., Lonnroos, E. and Euler-Chelpin, M. C. V., 2013, Prevalence of Depression among Older Adults with Dementia Living in Low- And Middle-Income Countries: A Cross-Sectional Study. European Journal of Public Health, Vol. 24 (1), 40-44.

Clarke, T. C., Schiller, J. S. and Boersma, P. B., 2019, Early Release of Selected Estimates Based on Data from the 2019 National Health Interview Survey. National Center for Health Statistics, Vol. 9(20), 1-2.

Centers for Disease Control and Prevention, 2020, Coronavirus (COVID-19). [Cited 1 July 2020]. Available from: https://www.cdc.gov/coronavirus/2019-ncov/dailylife-coping/managingstress-anxiety.html.

Department of Mental health, Ministry of Public Health, Thailand, 2020, The Exhalent Center For Depressive Disorders. [Cited 31 October 2020]. Available from: https://www.dmh.go.th/report/.

Denihan, A., Kirby, M., Bruce, I., Cunningham, C., Coakley, D. and Lawlor, B. A., 2000, Depressive Morbidity and Gender in Community-Dwelling Brazilian Elderly: Systematic Review and Meta-Analysis. International Psychogeriatric, Vol. 22(5), 712726. 
Ettman, C. K., Abdalla, S. A., Cohen, G. H., Sampson, L., Vivier, P. M., and Galea, S., 2020, Prevalence of Depression Symptoms in US Adults Before and During the COVID-19 Pandemic. JAMA Network Open, Vol. 3(9), 112.

Gustavson, K., Knudsen, A. K., Nesvag, R., Knudsen, G. P., Vollset, S. E. and Kjennerud, T. R, 2018, Prevalence and Stability of Mental Disorders among Young Adults: Findings from a Longitudinal Study. BMC Psychiatry, Vol. 18(65), 1-15.

Hu, Y., Li, P. and Martkainen, P., 2019, Rural-urban Disparities in Age Trajectories Of Depression Cases in Later Life: The China Health and Retirement Longitudinal Study. PLOS ONE, Vol. 14(4), 1-15.

Jia, R., Ayling, K., Chalder, T., Massey, A., Broadbent, E., Coupland, C. and Vedhara, K., 2020, Mental Health in the UK during the COVID-19 Pandemic: Cross-Sectional Analyses from a Community Cohort Study. $B M J$, Vol. 10, $1-14$.

Krendl, A.C. and Perry, B. L., 2020, The Impact of Sheltering in Place During the COVID-19 Pandemic on Older Adults' Social and Mental Well-Being. Gerontol B Psychol Sci Soc Sci, Vol. 1(1), 1-6.

Kim, A. W., Nyengerai, T. and Mendenhall, E., 2020, Evaluating the Mental Health Impacts of the COVID-19 Pandemic in Urban South Africa: Perceived Risk of COVID-19 Infection and Childhood Trauma Predict Adult Depressive Symptoms. NIH Preprint Pilot, 1-23.

Kumari, S. and Joseph, J., 2020, Comparison of Depression among the Elderly in a Selected Semiurban and Rural Community of Haryana, North India: A Cross-Sectional Survey. Journal of Geriatric Mental Health, Vol. 19, 33-37.

Liu, Q., Cai, H., Yang, L. H., Xiang, Y. B., Yang, G., Li, H., Gao, Y. T., Zheng, W., Susser, E. and Shu, X. O., 2018, Depressive Symptoms and their Association with Social Determinants and Chronic Diseases in Middle-Aged and Elderly Chinese People. Scientific RepOrTS, Vol. 8(3841), 1-11.

Li, L. W., Liu, J. L., Xu, H. and Zhang, Z., 2016, Understanding Rural-Urban Differences in Depressive Symptoms among Older Adults in China. J Aging Health, Vol. 28(2), 341-362.

Letter to the Editor, 2020, Psychological Impact of COVID-19 on Older Adults. Current Medicine Research and Practice, Vol.10, 201-202.
Miller, C. A., 2019, Nursing for Wellness in Older Adults. 8 ed. New York: Wolters Kluwer.

Malhotra R, Chan A. and Ostbye T., 2010, Prevalence and Correlates Of Clinically Significant Depressive Symptoms among Elderly People in Sri Lanka: Findings from A National Survey. Int Psychogeriatr, Vol. 22(2), 227- 236.

Nair, S. S., Raghunath, P. and Nair, S. S., 2015, Prevalence of Psychiatric Disorders among the Rural Geriatric Population: A Pilot Study in Karnataka, India. Central Asian Journal of Global Health, Vol. 4(1), 1-10.

Onuh, J. C., Mbah, P. O., Ajaero, C. K., Orjiakor, C. T., Igboeli, E. E. and Ayogu, C. K., 2021, Ruralurban Appraisal of the Prevalence and Factors of Depression Status in South Africa. Journal of Affective Disorders Reports, Vol. 4(2021), 1-9.

Pilania, M., Yadav, V., Bairwan, M., Behera, P., Gupta, S.D., Khuranu, H., Mohan, V., Baniya, G. and Poongothai, S., 2019, Prevalence of Depression among the Elderly (60 years and above) Population in India, 1997-2016: A Systematic Review and Meta-Analysis. BMC Public Health, Vol. 19 (832), 1-18.

Quin, X., Wang, S. and Hsieh, C. R., 2018, The Prevalence of Depression and Depressive Symptoms among Adults in China: Estimation based on a National Household Survey. China Economic Review, in Press.

Sinha, S., Sharivastava, S. and Ramasamy, J., 2013, Depression in an Older Adult Rural Population in India. MEDICC review, Vol. 15(4), 41-44.

Siriwanarangsun, P., Kongsuk, T., Arunpongpaisan, S., Kittirattanapaiboon, P., and Charatsingha, A, 2004, Prevalence of Mental Disorders in Thailand: A National Survey 2003. Journal of Mental Health of Thailand, Vol. 12(3), 176-185.

Srinivasan, M., Reddy, M. M., Sarkar, S. and Menon, V., 2020, Depression, Anxiety, and Stress among Rural South Indian WomenPrevalence and Correlates: A Community-Based Study. Journal of Neurosciences in Rural Practice, Vol. 11(1), 78-83.

Subramaniam, M., Abdin, E., Sambasivam, R., Vaingankar, J. A., Picco, L., Pang, S., Seow, E., Chua, B. Y., Magadi, H., Mahendran, R. and Chong, S. A., 2016, Prevalence of Depression among Olders-Results from the Wellbeing of the Singapore Elderly Study. Ann Acad Med Singapore, Vol. 45, 123-133. 
Vanoh, D., Shahar, S., Yahya, H.M. and Hamid., 2016, Prevalence and Determinants of Depressive Disorders among Communitydwelling Older Adults: Findings from the Towards Useful Aging Study. International Journal of Gerontology, Vol. 10, 81-85.

World Health Organization, 2017, Depression and Other Common Mental Disorders Global Health Estimates. Geneva: World Health Organization.

World Health Organization, 2021, Ageing and Health. [cited 21 September 2021]. Available from: https://www.who.int/news-room/factsheets/detail/depression.
World Health Organization, 2020, Depression. [cited 30 January 2020]. Available from: https://www.who.int/news-room/factsheets/detail/depression.

Zhou, X., Zhen, L., Yang, H., Song, H. and Sun, Y., 2014, The Prevalence and Risk Factors for Depression Symptoms in a Rural Chinese Sample Population. PLOS ONE, Vol. 9(6), 1-8. 